\title{
Melibea, Plácida y Serafina: tres muertes violentas en el primer teatro clásico
}

\author{
Laura Mier Pérez \\ Universidad de Cantabria \& IEMYR
}

Uno de los temas más presentes en el teatro renacentista, como ya señalara Gillet ${ }^{1}$ es la temática del suicidio vinculada directamente a los procesos amorosos que se recogen en el teatro profano. Generalmente la desesperación amorosa caracteriza a los personajes masculinos que la utilizan como herramienta fundamental en su proceso de recuesta, ya sea como mero artificio retórico o como consecuencia de su avanzado estado de enfermo mental provocado por la intensidad del sentimiento. Sin embargo, aunque sea en menor medida, también los personajes femeninos de la escena renacentista enferman de amor, lo que les lleva, en ocasiones, a contemplar o cometer suicidio como única salida al debate entre su honor y su amor, si bien es cierto que la amenaza no se incorpora a su discurso de enamorada. En este trabajo queremos analizar tres claros ejemplos de suicidio llevado a escena, comenzando por el modelo trágico que plantea Melibea, en la Tragicomedia de Calisto y Melibea, de Fernando de Rojas, hasta llegar al frustrado y cómico intento de Serafina en la Comedia Serafina de Bartolomé de Torres Naharro, pasando por el también trágico suicidio con final feliz de Plácida en la Égloga de Plácida y Vitoriano de Juan del Encina.

La muerte de Melibea solo puede ser comprendida desde la evolución de su personaje, por ser uno de los más perfectamente delineados de cuantos conforman el panorama renacentista, de ahí que nos tengamos que entretener brevemente en la comprensión de su enamoramiento para poder discernir de qué forma es tratado el motivo del suicido por Fernando de Rojas. En el caso de Melibea, además, hemos de tener en cuenta que es el personaje más complicado de entender por parte de la crítica del panorama teatral de principios del quinientos. El papel de la magia en su evolución psicológica ha generado numerosos estudios críticos a los que hemos de volver brevemente para considerar el desenlace coherente o no del personaje. 
La crítica se encuentra polarizada principalmente entre quienes creen en la influencia de la magia en el enamoramiento de Melibea y de ahí se explican su suicidio, como consecuencia de la mediación diabólica, ${ }^{2}$ y quienes ven en la intervención de Celestina un elemento innecesario para la trama argumental porque Melibea ya ha manifestado sus sentimientos desde la primera escena al preguntar inquisitivamente a Calisto - esa curiosidad que señaló Madariaga—. ${ }^{3}$ En tercer lugar se sitúan los trabajos que ven en la magia un elemento accesorio que solo precipita lo que ya estaba establecido, véase el caso de Ana Vian:

Tienden a considerarse autoexcluyentes la funcionalidad
de la magia y el poder de Celestina como agente psicoló-
gico en la intriga, aunque magia y psicología no se opo-
nen. [...] Pensar en un proceso latente en Melibea no es
antagónico con que Celestina lo precipite, aunque no lo
desencadene por completo. ${ }^{4}$

Otra de las cuestiones tremendamente interesantes para el tema que nos ocupa y que ha sido objeto de los intentos de comprensión sobre nuestro personaje es el papel del desmayo en el acto IV y su posible relación con la muerte final. De nuevo, la explicación más extendida desde el trabajo de Russell es la que la considera uno de los efectos de la magia de Celestina, así como aquellas que encuentran un anclaje literario pre-

2.- Aunque no fue el primer trabajo publicado en esta dirección, recuérdense las opiniones de Marcelino Menéndez Pelayo (Orígenes de la novela III. Cuentos y novelas cortas. La "Celestina", Madrid, CSIC, 1962) o las de Marcel Bataillon (La "Célestine» selon Fernando de Rojas, París: Didier, 1961) el panorama cambió completamente con el estudio de Peter Russell «La magia como tema integral de La Celestina», Studia Philologica: Homenaje a Dámaso Alonso, Madrid, Gredos, 1963, pp. 241-276. Revisado y ampliado en Temas de "La Celestina", Barcelona, Ariel, 1978. Para un estado de la cuestión más completo y un tratamiento más detallado de estas cuestiones remitimos al segundo capítulo de nuestra tesis doctoral, La representación del amor: motivos amorosos del teatro español en el primer tercio del siglo XVI, Universidad de Salamanca, 2015.

3.- Salvador Madariaga, «Melibea. Ganada es Granada», Mujeres españolas, Madrid, Espasa Calpe, 1972, pp. 367-383. En esta línea respecto al personaje de Melibea se sitúan, entre otros, los trabajos de Erna Ruth Bernt Amor, muerte y fortuna en "La Celestina", Madrid, Gredos, 1962; David William Foster, «Some Attitudes Towards Love in the Celestina», Hispania, 48.3 (1965), pp. 484-494; María Rosa Lida de Malikel, La originalidad artística de "La Celestina", Buenos Aires, EUDEBA, 1970 o Pierre Heugas, La "Célestine» et sa descendance directe, Burdeos, Institut d'Estudes Ibériques e Ibéro-Américaines de l'Université de Bordeaux, 1973, Emilio de Miguel, La "Celestina" de Rojas, Madrid: Gredos, 1996 y más concretamente, "Melibea en amores: vida y literatura 'faltándome Calisto, me falte la vida'», ed. Pilar Carrasco, El mundo como contienda. Estudios sobre "La Celestina", Anejo 31 Analecta Malacitana, Málaga, Universidad, 2000, pp. 29-66, por citar algunas de las obras clásicas. Los trabajos en esta dirección, aún con objetivos diversos, han continuado hasta nuestros días, especialmente tras el impulso de los estudios feministas sobre La Celestina de la década de los 90.

4.- Ana Vian, «Transformaciones del pensamiento mágico: el conjuro amatorio en la Celestina y su linaje literario», José Luis Canet \& Rafael Beltrán (eds.), Cinco siglos de "Celestina»: aportaciones interpretativas, Valencia, Universidad de Valencia, 1997, pp. 209-238; la cita en p. 211. 
cedente en la tratadística moral o en la tradición literaria del amor cortés. Sin embargo, en la línea interpretativa que acabamos de señalar independiente al proceso diabólico de la alcahueta, hay trabajos que plantean la relación de Melibea con su desmayo de forma muy diversa. José Javier Rodríguez Rodríguez retoma la idea de Lida de Malkiel, que veía en el vahído la manifestación física de la derrota moral de Melibea pero lo lleva más lejos, ya que ve en él la renuncia completa de Melibea al ser social que le estaba destinado ser, la dama. ${ }^{5}$

En este sentido, Lacarra defiende, en una profundización en el personaje de Melibea, la dicotomía amor-honor en la que se mueve la protagonista, enamorada desde la primera escena donde lo muestra en su coqueteo con Calisto. ${ }^{6}$ Además recalca cómo "el lenguaje eufemístico amoroso y el uso de los modos cortesanos [sirve] para disfrazar la lascivia y venderla como amor». ' Esta lascivia es especialmente significativa en Melibea como mujer, considerada tradicionalmente propensa a la voluptuosidad, como verán Sempronio y Celestina, quienes también «atribuyen una natural inclinación de la mujer hacia la lujuria y no diferencian a las rameras de las mujeres guardadas, salvo que en estas encarecen más su valor y tardan más en acceder a sus deseos libidinosos». ${ }^{8}$ Este sentimiento tendrá sus consecuencias, según el estudio de José Javier Rodríguez Rodríguez:

La rebeldía erótica de Melibea es destructiva, ya que al decidir cumplir su voluntad y tener una sexualidad y un amor como individuo y no como miembro del 'género femenino', no sólo pierde el poder como sujeto agente, ya mencionado, sino que confirma los supuestos que fundamentan la creencia de que las mujeres son naturalmente lujuriosas. ${ }^{9}$

Especialmente interesante nos parece la exploración que lleva a cabo la autora en la comprensión del personaje de Melibea desde las teorías médicas de la época, más concretamente, de sus patologías. ${ }^{10} \mathrm{El}$ análisis

5.- José Javier Rodríguez Rodríguez, «Sobre el desmayo de Melibea y otros extremos del honor», Ignacio Arellano \& Marc Vitse (coords.), Modelos de vida en la España del Siglo de Oro, Madrid, Universidad de Navarra \& Vervuert, 2004, pp. 11-25.

6.- Eukene Lacarra Lanz, «El erotismo en la relación de Calisto y Melibea», ed. Pilar Carrasco, El mundo como contienda. Estudios sobre "La Celestina", Málaga, Analecta Malacitana, anejo 31, 2000, pp. 127-145.

7.- Ibid., 144.

8.- Ibidem.

9.- Ibid., 145.

10.- Eukene Lacarra Lanz, «Las pasiones de Areúsa y Melibea», Ottavio Di Camillo \& John O'Neill, "La Celestina" 1499-1999. Selected Papers from the International Congress in Commemoration of the Quincentennial Anniversary of "La Celestina", Nueva York, Hispanic Seminar Medieval Studies, 2005, pp. 75-109. 
de la enfermedad de amor femenina, muy diferente a la masculina, nos sirve, según Lacarra, para ver cómo el amor hereos se consideraba una enfermedad típicamente masculina, de ahí que en las mujeres se fusionara con la histeria, ya que raramente se explicaba la psicología femenina a través de la enfermedad de amor. En el caso de Celestina analiza con detalle el caso de histeria, o mal de madre de Areúsa ${ }^{11}$ y la diferencia con los sentimientos de Melibea, que están más cercanos, efectivamente, a los de Calisto verdaderamente enfermo de amor. ${ }^{12}$ Esta línea interpretativa abre la posibilidad de que tanto el desmayo como el posterior suicidio sean simplemente consecuencias directas de la "desesperación» amorosa definida en términos distintos a los convencionales por tratarse de una protagonista femenina.

La exploración de las teorías médicas a propósito de Melibea resulta especialmente enriquecedora para la comprensión del personaje, no tanto porque expliquen su comportamiento, que también, sino porque, además, nuestra protagonista las conoce y las utiliza en su beneficio. Como ha analizado Emilio de Miguel, en el acto IV Celestina y Melibea desarrollan una "esgrima dialéctica» en la que ambas son conocedoras de su parte en el juego. ${ }^{13}$ Melibea, en defensa de su honor, que ya es secundario a su amor, necesita algo más que un confidente a quien exponer sus deseos, de tal forma que apela al sentimiento de misericordia hacia los enfermos, haciendo gala de su fe y posteriormente a la investidura de Celestina como médico, no como confidente. Cuando es Melibea quien vuelve a Celestina en el acto x, la enfermedad de amor agravada se convierte en su refugio retórico para poder acceder a Calisto. Como ha destacado Lacarra, al afi mar "pereció mi remedio", no está sino implicándose en una tradición que conocemos bien, la del amor hereos. Podemos afirma , pues, que el suicidio de Melibea es un acto consecuente con su trayectoria, ante la imposibilidad de conjugar las esferas pública y privada de su vida y la consecuencia de la coherencia de un personaje que decide vivir su creciente amor hasta las últimas derivaciones. ${ }^{14}$ Melibea utiliza al final de su vida dramática el monólogo para caracterizarse como enamorada de amor. La explicación a su padre sirve para entroncarla con la convención monológica dramática renacentista por excelencia, lo que garantiza la veracidad de los sentimientos al mismo tiempo que funciona a modo de confesión final

11.- Puede verse también James F. Burke, "The mal de la madre and the Failure of Maternal Influence in Celestina», Celestinesca, 17.2 (1993), pp. 111-128.

12.- Véase el análisis de Pedro Cátedra en Amor y pedagogía en la Edad Media, Salamanca: Ediciones Universidad de Salamanca, 1989 de la diferencia entre la Comedia y la Tragicomedia en el diseño del personaje de Calisto.

13.- "Melibea en amores...» especialmente, aunque es una idea que repite en varias de sus publicaciones.

14.- Véase nuestro trabajo "La conciencia de Melibea», Celestinesca, 32 (2008), pp. 231-243, donde analizamos con detalle el proceso de enamoramiento de la dama. 
Sin embargo, hay más cuestiones relevantes en este motivo dramático. Hay una clara interdependencia entre el impacto del suicidio y la adscripción genérica de la obra. Si Celestina es tragedia lo es, sobre todo, por la muerte de Melibea y, en menor medida, por la muerte de los demás personajes, por no haber sido parodiada en ningún momento. No tiene sentido entrar en disquisiciones genéricas sobre Celestina porque ya ha sido tratado con amplitud, simplemente queremos llamar la atención sobre la importancia de este motivo en el destino de la obra y en su recepción.

Reconocemos dos líneas interpretativas bien diferenciadas en cuanto a las implicaciones del suicidio de Melibea. Por un lado, tenemos la opinión de quienes ven en todo esto, por encima de todo, un producto literario, y es la propia literatura la que lo explica. Recordemos, en este sentido, lo que proponía Bataillon sobre el cambio que se produce de la comedia a la tragicomedia, condenando a nuestra protagonista, en la interpretación moralizante de la obra, aún más en la segunda por el carácter dilatado y aún más premeditado de su suicidio. Deyermond y Severin defienden que Melibea se suicida creyendo reunirse con Calisto en el infierno ${ }^{15} \mathrm{La}-$ carra vincula la determinación de quitarse la vida de Melibea con la influencia que la literatura ha ejercido en su idea de amante: «su decisión de suicidarse va acompañada de una fuerte idealización de su amado, en un movimiento de autoengaño que le permite mantener la ficción literaria que el lenguaje erótico-cortesano, nunca del todo abandonado, emulaba». ${ }^{16}$ Idea en la que incide en otro trabajo:

Melibea se ha inventado un Calisto a la medida de sus deseos y a la medida de los héroes de la literatura sentimental coetánea que él pretendió imitar, lo que le permite a ella misma morir como una heroína obscureciendo sus propias contradicciones e incluso su fracaso como dama, pues su amor e influencia no han servido para ennoblecer a Calisto, como diría Leriano, sino para envilecerlo y revelar su falta de virtud. Ambos han utilizado la literatura para justificar y disfrazar sus sentimientos y deseos de placer en un intento de hacerlos más respetables y alejados de la lujuria sin paliativos que caracteriza a los criados. Rojas, en cambio, parodia, desde la perspectiva de los diferentes puntos de vista que conlleva la estructura dialogada de la obra, la presunción de estos personajes de literaturizar la vida, nos revela la discre-

15.- Alan Deyermond, "Hacia una lectura feminista de La Celestina», ed. Françoise Maurizi, La Célestine. Comedia o tragicomedia de Calisto y Melibea. Actes du coloque international, Caen, Université de Caen, 1993, pp. 17-42 \& Dorothy Severin, «La parodia del amor cortés en La Celestina», Edad de Oro, 3 (1984), pp. 275-280.

16.- «El erotismo...», p. 143. 
pancia entre sus actos y su presunción y nos proporciona claves de la falacia del disfraz que adoptan. ${ }^{17}$

En otra línea totalmente diferente que no busca las explicaciones del suicidio de Melibea en las tradiciones literarias precedentes o coetáneas, Santiago López Ríos ha abierto el camino hacia la comprensión del Ars moriendi de la época, los usos y costumbres y la posible implicación social y cultural del suicidio de Melibea. ${ }^{18}$ Un documentado análisis sobre la muerte voluntaria en la Edad Media y las repercusiones sociales de este tipo de defunción le permite lanzar la hipótesis de las graves consecuencias que planteaba un suicido como el de Melibea, especialmente en cuanto a la honra. Para dilucidar si Pleberio era percibido como un personaje infamado por los primeros lectores de la Tragicomedia investiga sobre el tratamiento del suicidio en la mentalidad medieval. Resulta muy interesante que plantee cómo la conflictividad que presentaba, incluso simplemente para mencionarlo, obliga a la creación de una serie de eufemismos que acabarán consolidándose como referentes específicos al suicidio por amor, como es el caso del «desesperarse» que pasó de significar la ausencia de esperanza en la salvación para convertirse en un sinónimo de "suicidio». ${ }^{19}$

En un mundo en el que «el suicidio de una persona tenía consecuencias legales para sus parientes, consecuencias que podían llegar a incluir la pérdida de propiedad, pero lo peor era la vergüenza del castigo público que se podía aplicar al cuerpo del difunto» como colgar el cadáver de una soga, arrastrarlo por la calle o incluso quemarlo, no es difícil imaginar las implicaciones de un acto como el de Melibea que es, además, público. ${ }^{20}$ Además en el Ars moriendi se enfatizaba la necesidad de confia en Dios y su misericordia para luchar con las últimas tentaciones de los que agonizaban, especialmente en los «desesperados», ${ }^{21}$ lo que resulta radicalmente opuesto a la concepción de la enfermedad de amor enten-

17.- Eukene Lacarra, «La parodia de la ficción sentimental en La Celestina», Celestinesca, 13-1 (1989), pp. 11-30.

18.- "'Pon tú en cobro este cuerpo que allá baja': Melibea y la muerte infamante en la Celestina», ed. Pedro M. Piñero Ramírez, Dejar hablar a los textos: homenaje a Francisco Márquez Villanueva, Sevilla, Universidad, 2005, pp. 309-326.

19.- Véase, además, Alexander Murray, Suicide in the Middle Ages, Oxford: University Press, 1998 \& Ramón Andrés, Historia del suicidio en occidente, Barcelona, Península, 2003, entre otros.

20.- López Ríos, «Pon tú...», p. 314. En un ámbito más amplio puede verse también el fundamental trabajo de George Minois, History of Suicide: Voluntary Death in Western Culture, Baltimore \& Londres, John Hopkins University Press, 1999. Minois señala que la única forma de conseguir la herencia de un suicida era considerándolo loco, sino era confiscada.

21.- Véase Lacarra, «La parodia...» \& Roger Chartier, «Les arts de mourir, 1450-1600», Annales. Histoire, Sciences Sociales, 31.1 (1976), pp. 51-57. 
dida como pérdida absoluta de la voluntad del amante, tan presente en la dramaturgia renacentista. ${ }^{22}$

Pero es, desde nuestro punto de vista, el trabajo de Rebeca Sanmartín el que más ayuda a desenmarañar el complejo entramado sobre la muerte que Rojas lleva a escena. ${ }^{23} \mathrm{El}$ ambicioso proyecto de esclarecer las diferentes muertes de Celestina y sus implicaciones lleva a Sanmartín a tener en cuenta una serie de cuestiones, de gran importancia para comprender el suicidio de Melibea. En el intento de aclarar la moralidad implícita de la obra considera fundamental analizar la "puesta en escena del fin de la vida", para lo cual resulta imprescindible familiarizarse con los parámetros de la muerte en el siglo XV, que intentaremos reconstruir muy brevemente. ${ }^{24}$

Los cristianos temían morir de forma rápida e imprevista porque ponía en peligro la salvación, al no tener la oportunidad de hacer penitencia. Por tanto, la muerte ideal sería la que se producía en la cama con plena conciencia de su llegada, absolutamente opuesta a cualquiera de las muertes en Celestina.

En general el arrepentimiento caracteriza de forma tímida a los personajes de la Tragicomedia. Pero más aún en Melibea, en la que ese sentimiento no existe. Hace una suerte de confesión ante su padre, que ya hemos mencionado, en la que lo que demuestra es una consciencia profunda de sus actos, pero nada de contrición. ${ }^{25}$ Sanmartín insiste en la sorprendente y controvertida reacción de Pleberio para destacar la poca importancia que concede al suicidio de su hija, teniendo en cuenta que con él Melibea ha perdido doblemente su honra, ya que a los suicidas no se les da sepultura cristiana. Francamente extraordinaria es la falta de consideración del más allá en ambos, teniendo en cuenta la importancia del Ars moriendi que hemos señalado y la tradición elegíaca.

A la tradicional visión de la muerte de Melibea como epítome de la moralidad condenatoria de la pieza («en la obra se presenta un caso de amor di diletto que se reprueba. Como dice el 'Argumento' general, quienes lo hacen posible y quienes lo disfrutan, mueren; incluso quienes pecan por

22.- Véase especialmente Pedro Cátedra, Amor y pedagogía..., en lo referente a El Tostado, responsable de esta reformulación y su éxito en la Península Ibérica.

23.- «Sobre el teatro de la muerte en La Celestina: El cuerpo «hecho pedazos» y la ambigüedad macabra», eHumanista, 5 (2005), pp. 113-125. Véanse también «Desarmando el rostro de la muerte: El ritual alegórico del Ars moriendi», Iberorromania, 60 (2004), pp.42-58 \& El arte de morir. La puesta en escena de la muerte en un tratado el siglo XV, Madrid: Iberoamericana, 2006.

24.- «Sobre el teatro...», p. 113. Sobre la muerte de Celestina véase también Joseph Snow, "Confederación e ironía: crónica de una muerte anunciada (Celestina, autos I-XIII), Celestinesca, 37 (2013), pp. 119-138.

25.- En esta línea se sitúan también los trabajos de Peter N. Dunn, en el que Sanmartín basa buena parte de sus reflxiones, "Pleberio's World», Papers of the Modern Language Association, 91 (1976), pp. 406-419 y de Joseph Snow, «Two Melibeas», Ana Menéndez Collera \& Victoriano Roncero López (eds.), Nunca fue pena mayor: Estudios de literatura española en homenaje a Brian Dutton, Cuenca, Ediciones de la Universidad de Castilla-La Mancha, 1996, pp. 655-662. 
omisión Pleberio y Alisa, también son censurados» $\left.{ }^{26}\right)$, Sanmartín añade un nuevo elemento. La moralidad de la obra no reside ni en el monólogo de Melibea, ni en su forma de morir, sino en "la presentación del cuerpo muerto" ${ }^{27}$ es decir, en cómo queda el cadáver. Todos los cuerpos de los personajes aparecen «mutilados, rotos, despedazados», incluido el de Melibea que se parte en pedazos: ${ }^{28}$

Los cuerpos muertos de La Celestina se hacen así simbólicos, espacio del castigo del asesinato, la locura de amor o la alcahuetería. Aunque en esta obra no se dé tanta profusión de elementos simbólicos como en las novelas sentimentales, en el mundo tardomedieval es difícil desasirse de ellos. ${ }^{29}$

Esta simbología, especialmente en el caso de Melibea en el que la muerte de Calisto no ha hecho más que reafirmar su presencia terrenal y olvidar aún más los bienes celestiales lleva a Sanmartín a concluir que:

Los cuerpos muertos y mutilados de Celestina no son relacionados por los personajes con el más allá, sino sólo con el más acá. La lección cristiana de lo macabro (el memento mori) puede volverse así una invitación a la significación inversa (memento vivere). Y la moral del castigo puede quedarse un instante detenida en la mirada consternada por el encantamiento que ejerce el erotismo mórbido que recorre la cultura macabra. ${ }^{30}$

Es decir, la falacia del ejemplo a contrario puede llevar a ser modelo de lo opuesto. Sigue siendo ambigua la intencionalidad de Rojas, incluso si tomamos por suyas sin ninguna duda las palabras de los preliminares. ${ }^{31}$

A pesar de que haya cuestiones que aún hoy nos resultan complicadas de comprender perfectamente, como la reacción de Pleberio, tan vinculada al destino de la obra, ya sea por el acierto de Rojas de individualizar a sus personajes hasta extremos desconocidos en el momento, como ha

26.- Eukene Lacarra, "La muerte irredenta de Melibea», Actas del Simposio Internacional 15022002: Five Hundred Years of Fernando de Rojas' "Tragicomedia de Calisto y Melibea", ed. Juan Carlos Conde, Nueva York, Hispanic Seminar of Medieval Studies, 2007, pp. 173-207. Creemos que esta cita resume la aproximación más tradicional al carácter ejemplarizante de la muerte de nuestra protagonista.

27.- «Sobre el teatro...», p. 117.

28.- «Sobre el teatro...», p. 117.

29.- Ibid. p. 119.

30.- Ibid, p. 121.

31.- Recuperan estas reflexiones en cierta medida lo que planteaba Cándido Ayllón en "Death in Celestina», Hispania, 41.2 (1958), pp. 161-164, sobre la relación entre el carpe diem y la muerte en nuestra obra. 
señalado Frank P. Casa, ${ }^{32}$ ya sea por la influencia del Petrarca latino, como sugiere Sanmartín, lo que no podemos perder de vista es que estamos ante un texto literario que, además, termina en este momento. Las consecuencias no son importantes porque lo que sucede después no se cuenta. La historia ha terminado porque han muerto sus protagonistas, aunque haya personajes que los sobrevivan. De ahí la tentación que generó Rojas, como pocos autores, para escritores posteriores que han querido continuar la obra. Las buenas muertes, las que siguen el Ars moriendi son probablemente todas las que no es necesario contar en la ficción dramática

Como viene siendo un lugar clásico de la crítica celestinesca, la mejor forma de cerrar las consideraciones sobre cualquier motivo de la obra, suele ser echar una mirada a lo que hacen las obras que la suceden, ya que ahí reside la clave interpretativa más inmediata. En este sentido ya Menéndez Pelayo insistía en Melibea como modelo para Plácida, como veremos a continuación. Lida no veía una contradicción en el sentimiento religioso de Melibea, elemento caracterizador del personaje en la investigación de la hispanista argentina: "Su religión muy sincera - la decisión de quitarse la vida no le impide ofrecer devotamente su alma a Diosdestaca, pues, por su cariz social, no moral ni místico». ${ }^{33}$

Heugas, el gran estudioso de la celestinesca, señala que es precisamente el suicido lo que más divide a los imitadores y continuadores de Celestina, decantando la balanza hacia imitaciones trágicas o cómicas. Destaca, además, la diferencia que hay en los suicidios literarios precedentes, principalmente masculinos y el de la Tragicomedia. También considera la muerte de las heroínas melibeanas como un triunfo del bien sobre el mal, como algo ejemplar y relacionada con las pasiones extremas. Sirve, pues, para condenar la pasión, el loco amor. Estas consideraciones nos devuelven, claro, a la concepción moralizante de Celestina y a su claro carácter de ejemplo a contrario. En cualquier caso, lo que está claro es que nos encontramos con un modelo literario extremadamente tentador que será llevado a escena reiteradamente por los dramaturgos inmediatamente posteriores a Fernando de Rojas, cuyo planteamiento teatral es extremadamente ambicioso, hasta tal punto, que será difícil la imitación plena, como en prácticamente todos los aspectos de La Celestina.

Uno de estos ejemplos es, precisamente, el suicidio de Plácida en la Égloga de Plácida y Vitoriano de Juan del Encina. El mayor interés despertado por la crítica ha sido el de dilucidar las fuentes literarias, labor en la cual debemos volver sobre los pasos ya recorridos de Melibea y las consideraciones ya mencionadas de Menéndez Pelayo y completar con las filiaciones con la pareja ovidiana de Píramo y Tisbe que apuntó Mac- 
Grady y desarrolló Kidd. ${ }^{34}$ Sin embargo, creemos de vital importancia la consideración de esta pieza como un espectáculo teatral para su correcta interpretación, especialmente en uno de los pasajes que analizamos a propósito de la temática que aquí nos ocupa, la Vigilia por la enamorada muerta: escollo hermenéutico para la crítica sólo comprensible desde su dimensión performativa.

Plácida es presentada como una heroína y su suicidio constituye el elemento más determinante de esta heroicidad. ${ }^{35}$ Es fácilmente asumible que los receptores del espectáculo trazaran el paralelo entre el suicidio de la escena y las suicidas clásicas de amor aciago Medea, Filis o Dido en cuanto al motivo del cuchillo y las circunstancias en las que se desarrolla. ${ }^{36}$

La muerte a cuchillo, a diferencia de las bestias que no podían morir de esta manera, marca la forma más honorable de encarar el suicidio para los estoicos, de ahí que los nobles en la antigüedad se suicidaran de esta manera, quedando reflejado así en la literatura clásica. En el extremo contrario se situaría el ahorcamiento, como peor muerte posible. El tratamiento serio que lleva a cabo Encina respeta, pues, estas convenciones: Plácida utiliza el cuchillo de Vitoriano, al contrario que el protagonista que comienza la búsqueda paródica de la herramienta apropiada. Albalá, al respecto, apunta lo siguiente:

En el ambiente cultural inmediato a la puesta en escena de las obras de Encina y de Naharro obras como La Celestina habían dignificado el individualismo de la heroína que decide poner fin a su propia vida, al tiempo que la condena firme del suicidio por Tomás de Aquino sería matizada en más de una ocasión [...] De ahí que asome el suicidio de

34.- Donald McGrady, "An Unperceived Popular Story in Encina's Plácida y Vitoriano», Bulletin of the Comediantes, 32 (1980), pp. 139-141; Michael Kidd, "Myth, Desire, and Play of Inversion: The Fourteenth Eclogue of Juan el Encina», Hispanic Review, 65.2 (1997), pp. 217-236. Ann E. Wiltrout estudia el suicidio desde la perspectiva de la contemplación, el cumplimiento y la resurrección, "Quien espera desespera: el suicidio en el teatro de Juan del Encina", Hispanófila, 72 (1981), pp. 1-13. Contempla el suicidio desde la tradición literaria pastoril de la Edad Media Mia Irene Gerhardt, Essai d'analyse littéraire de la pastorale dans les littératures italienne, espagnole et française, Utrecht, Hes Publishers, 1975, especialmente en las pp. 138-140 que pertenecen al capítulo que más nos interesa, "La pastorale espagnole», pp. 130-205.

35.- Para un tratamiento más amplio del suicidio y del sentido general de la obra de Encina remitimos a nuestro trabajo La temática amorosa del teatro del siglo XVI en la "Égloga de Plácida y Vitoriano" de Juan del Encina y la anónima "Comedia Serafina", Vigo, Academia Editorial del Hispanismo, 2016, en prensa.

36.- Véase la tesis doctoral de Marta Albalá Pelegrín, De la Península Ibérica a Italia: Concepción y práctica teatral de las primeras comedias castellanas, Graduate Center de la City University of New York, 2013, especialmente «Suicidas en la curia», pp. 134-163, estudio fundamental para nuestra comprensión de este motivo, cuya copia fue amablemente facilitada por la autora. Además, remitimos al análisis más extenso que llevamos a cabo de esta égloga en La representación del amor, Vigo, Academia Editorial del Hispanismo, 2016, en prensa. 
Plácida, si bien de manera momentánea, un ápice de admiración filtrado a través de la mitología clásica ${ }^{37}$

Otra de las cuestiones que la crítica ha señalado es la más que probable sensualidad de la escena: ${ }^{38}$

\author{
Por menos embaraçarme \\ en los miembros impedidos, \\ para más presto matarme, \\ muy bien será desnudarme \\ y quitarme los vestidos \\ que me estorvan (vv. 1288-1293). ${ }^{39}$
}

Durante toda la Vigilia por la enamorada muerta Plácida permanece desnuda o semidesnuda en el escenario antes de que Vitoriano la cubra para protegerla de los posibles animales salvajes. ${ }^{40}$

En el caso de la Égloga de Encina vemos cómo el suicidio de la protagonista dista mucho de los tratamientos paródicos posteriores, a pesar de los atisbos perpetrados por Encina con el personaje de Vitoriano y el contrapunto de los pastores rústicos, y está muy vinculado al carácter trágico-amoroso heredado de Melibea. Sin embargo, el aroma de tragedia desaparece por la intervención de los dioses, que devuelven a la vida a estos enamorados que habían decidido vivir sus sentimientos hasta las últimas consecuencias. El final feliz solo se consigue a través del artificio del deus ex machina.

Por otro lado, hemos de tener en cuenta, también a diferencia del modelo precedente, el carácter profundamente espectacular del texto de Encina. Plácida y Vitoriano se concibe como un espectáculo global en el que la danza y la música, no solo el texto, adquieren una dimensión tan importante que su comprensión solo es posible de esta manera, especialmente los momentos más estáticos de la misma. ${ }^{41}$ El suicidio de Plácida, con su mo-

\title{
37.- Albalá, De la Peninsula Ibérica..., p. 162
}

38.- La idea fue apuntada ya por Kidd y retomada con tino por Albalá (p. 147): hay que presuponer "todo un proceso altamente sexualizado por el que nos conduce su soliloquio: un proceso en el que la audiencia vería a Plácida tentando su pecho, gimiendo, intentando alcanzar su corazón y, para bien hacerlo, quitándose ropa en escena». El potencial sexual de la escena está refutado, según Albalá, por la inclusión del pliego que conservamos en la Biblioteca Nacional junto a un contrafactum erótico de López de Yanguas que apunta a la posible recepción del códice y por la posible representación en enero de 1513 en casa del cardenal Arbolea, como parece aceptar la crítica, ante un público que contaba con la presencia de prostitutas.

39.- Las citas están tomadas de la edición de Alberto del Río, Teatro, Barcelona: Crítica, 2001.

40.- Albalá llega a sugerir intenciones necrofílicas por parte de Vitoriano, como había adelantado el pastor del introito: «tomándole primero la fe de no hacer ningún desconcierto de su persona» (p. 180).

41.- Profundizamos en esta idea en nuestra tesis doctoral, La representación del amor: temas y motivos amorosos del teatro español en el primer tercio del siglo XVI, Universidad de Salamanca, 2015, de donde provienen algunas de las cuestiones aquí planteadas. 
nólogo, no deja de ser un eslabón más de esta performance, que en gran medida es posible por la influencia de Celestina, ya que el motivo del suicidio heredado de las comedias elegíacas de tradición ovidiana es popularizado por la obra de Rojas y será muy frecuente en el teatro, tanto por alusión, forma en la que se convierte en un auténtico lugar común de las piezas de temática amorosa, como en su pleno desarrollo como motivo dramático.

En tercer lugar queremos hacer referencia a uno de los tratamientos paródicos del motivo del suicidio más conseguidos de los que encontramos en el teatro del primer tercio del siglo Xvi. Nos referimos al intento de suicidio que lleva a cabo Felicina en la Comedia Aquilana de Bartolomé de Torres Naharro.

Dentro de la parodia anticortesana del pacense, elemento, en cierta medida, estructurador de toda la radical propuesta amorosa y matrimonial que late en este texto, la muerte, $y$, en concreto, la muerte por amor, es presentada como uno de los motivos más extremos. La muerte de Aquilano está fuertemente vinculada al desarrollo de la enfermedad de amor. Sin embargo, al igual que pasaba en La Celestina, la muerte de Felicina poco tiene que ver con esta tradición erotológico-literaria y mucho con los moldes precedentes de Melibea y Plácida, que conforman el marco perfecto para establecer la parodia.

La popularidad progresiva del tema del suicidio en escena lleva consigo la más perfecta codificación, de tal forma, que el motivo del cuchillo se convierte en un lugar común que permite la identificación inmediata de las intenciones suicidas de los personajes renacentistas, tanto en personajes femeninos como masculinos. Felicina es incapaz de llevar a cabo sus intenciones por no encontrar una soga con la que ahorcarse o por no encontrar un cuchillo lo suficientemente afilado. Además, nos encontramos con un personaje cuyo tratamiento paródico reside exclusivamente en este momento de la obra, con lo que el cariz cómico queda doblemente destacado por el contraste con el resto, destacado, a su vez, por la interrupción de Dandario, pastor rústico.

En las tres obras que hemos mencionado anteriormente encontramos tres formas diferentes de suicidio que corresponden a tres maneras distintas de hacer teatro en el primer tercio del siglo XVI y, a su vez, en tres desenlaces teatrales divergentes. El carácter eminentemente trágico de $\mathrm{La}$ Celestina queda perfectamente delimitado por la seriedad del motivo del suicidio en el personaje femenino, mucho más que por la muerte accidental de Calisto. En el caso de Encina, el recurso del deus ex machina previene la tragedia, quedando el suicidio definido como un motivo serio, pero no trágico. Por último, Torres Naharro propone una desviación considerable de los modelos precedentes, arraigando fuertemente el motivo en el carácter cómico de la obra. La temática amorosa del extremeño se asienta sobre las bases de la comicidad bajo la cual reina una propuesta moral 
concreta, ${ }^{42}$ también en lo referido a un asunto tan sumamente serio como podría parecerlos el suicidio.

Debemos retomar, además, algunas de las consideraciones con las que abríamos este trabajo. A propósito de Melibea hemos podido ver la importancia del desarrollo de la enfermedad de amor femenina para comprender la coherencia del personaje. Las mismas apreciaciones deberían extenderse a las otras dos protagonistas de las que nos hemos ocupado, Plácida y Felicina, aunque haya sido de manera mucho más somera. Aunque no se explicite, y al igual que sucede con los personajes masculinos, la muerte, como parte de la dialéctica y como motivo real en escena, está estrechamente vinculada al padecimiento de los enfermos de amor. A pesar de las diferencias significativas en la concepción filosófic y médica de hombres y mujeres durante el siglo xVI, podemos apreciar cómo se extiende el modelo literario de unos y a otras. Es decir, los personajes femeninos se benefician del desarrollo profuso del amor hereos que sufren sus enamorados masculinos de tal forma que no es necesario un desarrollo tan extenso del mismo motivo. A excepción de Melibea, ningún personaje femenino del teatro del primer tercio de quinientos alcanza la complejidad y la profundidad psicológica, aunque sea estereotipada, de la que sí disfrutan los compañeros masculinos. No obstante, podemos afirma, que el motivo de la enfermedad de amor está presente también en los personajes femeninos, aunque su apreciación se vea simplemente a través de pinceladas caracterizadoras, lo que viene a garantizar la veracidad de los sentimientos de nuestras heroínas renacentistas, independientemente del tratamiento serio o cómico bajo el que se presentan.

42.- Remitimos, una vez más, a lo expuesto tanto en nuestra tesis doctoral como en nuestro trabajo "La palabra inconveniente en Bartolomé de Torres Naharro», Atlante, 4 (2016), en prensa. 


\section{Bibliografía}

Albalá Pelegrín, Marta, De la Península Ibérica a Italia: Concepción y práctica teatral de las primeras comedias castellanas, Graduate Center de la City University of New York, 2013.

Ayllón, Cándido, "Death in Celestina», Hispania, 41.2 (1958), pp. 161-164. Bataillon, Marcel, La "Célestine» selon Fernando de Rojas, París: Didier, 1961.

Bernt, Erna Ruth, Amor, muerte y fortuna en "La Celestina», Madrid, Gredos, 1962.

Burke, James F. "The mal de la madre and the Failure of Maternal Influence in Celestina», Celestinesca, 17.2 (1993), pp. 111-128.

CASA, Frank P., "Pleberio's Lament for Melibea», Zeitschrift für Romanische Philologie, 84 (1968), pp. 20-29.

CÁtedra, Pedro, Amor y pedagogía en la Edad Media, Salamanca: Ediciones Universidad de Salamanca, 1989.

Chartier, Roger, "Les arts de mourir, 1450-1600», Annales. Histoire, Sciences Sociales, 31.1 (1976), pp. 51-57.

Deyermond, Alan, "Hacia una lectura feminista de La Celestina»,ed. Françoise Maurizi, La Célestine. Comedia o tragicomedia de Calisto y $\mathrm{Me}$ libea. Actes du coloque international,Caenç, Université de Caen, 1993, pp. 17-42.

Dunn, Peter N., "Pleberio's World", Papers of the Modern Language Association, 91 (1976), pp. 406-419.

Encina, Juan del, Teatro, ed. Alberto del Río, Barcelona: Crítica, 2001.

Foster, David William, "Some Attitudes Towards Love in the Celestina", Hispania, 48.3 (1965), pp. 484-494.

Gillet, Joseph E. Torres Naharro and the Drama of the Renaissance, Philadelphia, University Press, 1961.

GerHard, Mia Irene, Essai d'analyse littéraire de la pastorale dans les littératures italienne, espagnole et française, Utrecht, Hes Publishers, 1975.

Heugas, Pierre La "Célestine» et sa descendance directe, Burdeos, Institut d'Estudes Ibériques e Ibéro-Américaines de l'Université de Bordeaux, 1973.

KIDD, Michale, «Myth, Desire, and Play of Inversion: The Fourteenth Eclogue of Juan el Encina», Hispanic Review, 65.2 (1997), pp. 217-236.

LACARRA LANZ, Eukene, "La parodia de la ficción sentimental en La Celestina», Celestinesca, 201 (1989), pp. 11-30:29.

—, "El erotismo en la relación de Calisto y Melibea», ed. Pilar Carrasco, El mundo como contienda. Estudios sobre "La Celestina», Málaga, Analecta Malacitana, anejo31, 2000, pp. 127-145. 
Lacarra Lanz, Eukene, "Las pasiones de Areúsa y Melibea», Ottavio Di Camillo \& John O'Neill, "La Celestina" 1499-1999. Selected Papers from the International Congress in Commemoration of the Quincentennial Anniversary of "La Celestina", Nueva York, Hispanic Seminar Medieval Studies, 2005, pp. 75-109.

—, "La muerte irredenta de Melibea», Actas del Simposio Internacional 15022002: Five Hundred Years of Fernando de Rojas' "Tragicomedia de Calisto y Melibea», ed. Juan Carlos Conde, Nueva York, Hispanic Seminar of Medieval Studies, 2007, pp. 173-207.

Lida De Malikel, María Rosa, La originalidad artística de "La Celestina», Buenos Aires, EUDEBA, 1970.

López-Ríos Moreno, Santiago, "Pon tú en cobro este cuerpo que allá baja»: Melibea y la muerte infamante en la Celestina», ed. Pedro M. Piñero Ramírez, Dejar hablar a los textos: homenaje a Francisco Márquez Villanueva, Sevilla, Universidad, 2005, pp. 309-326.

Madariaga, Salvador de, "Melibea. Ganada es Granada», Mujeres españolas, Madrid, Espasa Calpe, 1972, pp. 367-383.

McGrady, Donald, "An Unperceived Popular Story in Encina's Plácida y Vitoriano", Bulletin of the Comediantes, 32 (1980), pp. 139-141.

Menéndez Pelayo, Marcelino, Orígenes de la novela III. Cuentos y novelas cortas. La "Celestina", Madrid, CSIC, 1962.

Mier Pérez, Laura, "La conciencia de Melibea», Celestinesca, 32 (2008), pp. 231-243.

- La representación del amor: motivos amorosos del teatro español en el primer tercio del siglo XVI, Universidad de Salamanca, 2015.

—, La temática amorosa del teatro del siglo XVI en la "Égloga de Plácida y Vitoriano" de Juan del Encina y la anónima "Comedia Serafina", Vigo, Academia Editorial del Hispanismo, 2016, en prensa.

-, "La palabra inconveniente en Bartolomé de Torres Naharro", Atlante, 4 (2016), en prensa.

Miguel, Emilio de, La "Celestina" de Rojas, Madrid: Gredos, 1996.

—, «Melibea en amores: vida y literatura 'faltándome Calisto, me falte la vida'", ed. Pilar Carrasco, El mundo como contienda. Estudios sobre "La Celestina", Anejo 31 Analecta Malacitana, Málaga, Universidad, 2000, pp. 29-66

MinOIs, George, History of Suicide: Voluntary Death in Western Culture, Baltimore \& Londres, John Hopkins University Press, 1999.

MurraY, Alexander, Suicide in the Middle Ages, Oxford: University Press, 1998 \& Ramón Andrés, Historia del suicidio en occidente, Barcelona, Península, 2003.

Rodríguez Rodríguez, José Javier, "Sobre el desmayo de Melibea y otros extremos del honor", Ignacio Arellano \& Marc Vitse (coords.), Modelos de vida en la España del Siglo de Oro, Madrid, Universidad de Navarra \& Vervuert, 2004, pp. 11-25. 
Russell, Peter, «La magia como tema integral de La Celestina», Studia Philologica: Homenaje a Dámaso Alonso, Madrid, Gredos, 1963, pp. 241-276. Revisado y ampliado en Temas de "La Celestina", Barcelona, Ariel, 1978.

SANMARTÍn BASTIDA, Rebeca, "Sobre el teatro de la muerte en La Celestina: El cuerpo «hecho pedazos» y la ambigüedad macabra», eHumanista, 5 (2005), pp. 113-125.

-, «Desarmando el rostro de la muerte: El ritual alegórico del Ars moriendì. Iberorromania 60 (2004): 42-58 \& El arte de morir. La puesta en escena de la muerte en un tratado el siglo XV, Madrid: Iberoamericana, 2006.

SeVErin, Dorothy, "La parodia del amor cortés en La Celestina», Edad de Oro, 3 (1984), pp. 275-280.

Snow, Joseph, "Two Melibeas», Ana Menéndez Collera \& Victoriano Roncero López (eds.), Nunca fue pena mayor: Estudios de literatura española en homenaje a Brian Dutton, Cuenca, Ediciones de la Universidad de Castilla-La Mancha, 1996, pp. 655-662.

- , "Confederación e ironía: crónica de una muerte anunciada (Celestina, autos I-XIII), Celestinesca, 37 (2013), pp. 119-138.

VIAN, Ana, «Transformaciones del pensamiento mágico: el conjuro amatorio en la Celestina y su linaje literario", José Luis Canet \& Rafael Beltrán (eds.), Cinco siglos de "Celestina»: aportaciones interpretativas, Valencia, Universidad de Valencia, 1997, pp. 209-238.

Wiltrout, Ann E., "Quien espera desespera: el suicidio en el teatro de Juan del Encina", Hispanófila, 72 (1981), pp. 1-13. 

Mier Pérez, Laura, «Melibea, Plácida y Serafina: tres muertes violentas en el primer teatro clásico», Celestinesca 40 (2016), pp. 117-134.

\section{RESUMEN}

El motivo del suicidio está muy presente en los personajes masculinos del teatro escrito en el primer tercio del siglo XVI. Sin embargo, su presencia en los personajes femeninos ha sido poco atendida. En este trabajo planteamos un estudio de tres suicidios por amor en tres obras muy cercanas cronológicamente: la Tragicomedia de Calisto y Melibea de Fernando de Rojas, la Égloga de Plácida y Vitoriano de Juan del Encina y la Comedia Serafina de Bartolomé de Torres Naharro desde la perspectiva de la enfermedad de amor y desde la configuración genérica de cada una de las piezas, de forma que podemos constatar la solidez del motivo también en los personajes femeninos.

PALABRAS CLAVE: Suicidio, teatro renacentista, celestinesca, enfermedad de amor.

\section{ABSTRACT}

The motif of suicide is commonly present among male characters in Spanish theatre written in the first third of $16^{\text {th }}$ century. However, its presence among female characters has been under-appreciated. In this paper we develop an a study about three suicides caused by love in three plays from a similar time period: the Tragicomedia de Calisto y Melibea, by Fernando de Rojas, the Égloga de Plácida y Vitoriano by Juan del Encina and the Comedia Serafina, by Bartolomé de Torres Naharro. For this analysis we take into consideration the perspective of lovesickness and the genre of each play in order to highlight the import of the motif of suicide with female characters.

KEY WORDS: Suicide, Renaissance theatre, celestinesca, lovesickess.

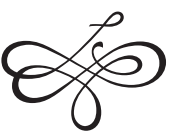

